\title{
The Language of Literacy Teaching and Learning in a Multilingual Classroom: Is Silozi Appropriate in the Zambezi Region of Namibia?
}

\author{
Begani Ziambo Mashinja*, David Sani Mwanza \\ University of Zambia
}

*Corresponding Author: Begani Ziambo Mashinja, University of Zambia

\begin{abstract}
Language planning and teaching has been premissed on a monolingual bias and the exclusive use of a predominant language has been percieved as a suitable practice to ensure inclusiveness, epistemic access and language learning success in mulitilingual classrooms. Zambezi education region is multilingual and SiLozi is the sole language of instruction for initial literacy in the junior primary grounded on the notion that it is the predominant local language. Drawing on Ruiz' Three Language Orintation framework, the study intended to assess the familiarity of learners and teachers with SiLozi language of instruction for initial literacy and the implication of their familiarity on epistemic access and initial literacy development in selected multilingual pre-primary classrooms in Sibbinda circuit of Zambezi region. A mixed methods study involving 6 pre-primary classrooms with 168 pre-primary learners, 6 pre-primary teachers and 6 school principals were sampled. Data were collected through a familiar language test, observations and interviews. The findings showed that pupils were not familiar with the official language of instruction which in itself, has a number of pedagogical implications. The results showed that pupils use their linguistic resources to access the target language and ensure epistemic access and initial literacy development. As a conclusion, the study argue that the exclusive use of SiLozi as medium of instruction for initial literacy is not a realistic view of the linguistic realities both inside and outside the multilingual pre-primary classroom, thus it is not appropriate.
\end{abstract}

Keywords: Initial literacy, Language of instruction, Familiar language, Language as resource, Translanguaging, SiLozi

\section{BACKGROUND}

Language is a very important tool to development because it is through language that the Vision 2030 for Namibia can be made a reality. If language of instruction is unfamiliar to the pupils as core recipients of the instruction, basic literacy goal of being a knowledge society becomes a nightmare. Therefore, there is need to understand the familiarity of both the teachers and learners with the language of instruction. Research has shown that language is very significant especially in the early stages of a child's education. Hence, since 1953, UNESCO has encouraged mother tongue instruction in early childhood and primary education. This implies that when a child is taught in a language that he/she is familiar with, learning is made easier because concepts will be easily understood. Thus, children's familiar language is the most efficient medium for early literacy and content instruction. The Namibian language policy stipulates that mother tongue should be used as the language of instruction in the junior primary. However, the policy only makes provision for the language of the majority group in that community to be selected as the language instruction, therefore implies that not all learners are then taught in their home language (Koker 2019, Iitula 2016, lipinge, 2013, Harris, 2011). Premised on the notion that SiLozi was the predominant language in multilingual Zambezi region, it is accorded the status of national language and recognised as sole medium of instruction in the junior primary in the Zambezi region. Although Silozi, is used for communication in the region, it is not an indigenous Namibian language, it is considered by others as a foreign language of Zambian origin functioning as a type of lingua franca in Zambezi (Nzwala, 2015; Totemeyer, 2010). This means that majority of the children do not have access to an education in a language they understand because almost 80 percent of the learners in Zambezi being taught in SiLozi, have other home languages (Kangumu, 2009:7). 
It is important to mention that SiLozi was chosen over and above other indigenous languages as medium of instruction for some reasons. As mentioned earlier, SiLozi was regarded as the predominant local language in the region. This means that of all the other local languages, SiLozi was seen as the most familiar local language appropriate to serve as medium of instruction. In other words familiarity was one characteristic that was considered for SiLozi to be selected. This implied that the local language to be chosen was supposed to be a language with which the people of the Zambezi region had some familiarity and with which there had been some educational experiences in the education system. Therefore, the motive of selecting SiLozi as language of instruction was that people of Zambezi region had some familiarity with the language due to the exposure they received in school. During the missionary era, SiLozi served as language of teaching and learning in mission schools where they taught basic literacy to the younger generation (Sitwala, 2010; Mbala, 1996). Maclaren (1958) explains that the materials and teachers used in the mission schools, were all imported from Zambia and Zimbabwe. As a result, SiLozi language developed rapidly in the region and gained ample status as the language of education. Moreover, during the South African colonial regime, SiLozi was inaugurated as medium of instruction in schools because of its closeness to Sotho (Northern Pedi) (Kangumu, 2008). Therefore, during this apartheid era, materials and teachers were readily available in the Sotho language and these would therefore be imported in from South Africa and taught SiLozi in Zambezi (Caprivi) region. Thus, SiLozi's support was due to the availability of orthography and teaching and learning materials as compared to other local familiar language in the region.

However, while lack of standardisation of most familiar languages is arguably used by authorities as fundamental reasons to base their excuse (Tötemeyer, 2010), today there exist the Subia (ChiKuhane) and Yeyi orthographies but these are just documents laying on shelves, they are not used to teach mother tongue nor familiar language in schools. The reasons for this are politically based. According to Kangumu (2008), SiLozi was seen as a mediator to help harmonise or rather overcome the seemingly antagonism and tribal tensions between the Masubia and Mafwe people. Thus, Silozi had been considered "neutral" in the region and it was therefore selected in connection to "language" harmonisation for educational purposes and regional unity (Kavhura, 2018; Steigertahl, 2018). Benjamin (2004:15) argued that the language policy's main objective was to unite and harmonize the Namibian people of different linguistic backgrounds and avoid tribalism that will oppose national unity in education, economic, politics and social sectors. Therefore, it can be argued that SiLozi was not intended for the purpose of initial literacy development and progression in the academic endeavours of pupils as supposed by the politician and educators but to serve for political reasons. Hence, SiLozi is a bone of contention in the region. The spread of SiLozi in the Zambezi education region was thus due to the conception or delusion that it met the criterion of being the predominant local familiar language and therefore it would stabilize the tribal tensions in the region harmonize and unity the people politically and academically. Therefore, it was appropriate as local language of instruction for initial literacy in school, particularly in the early phase of primary education in the Zambezi education region.

Considering that Zambezi education region is multilingual and different languages and varieties are predominant in various communities and SiLozi is the sole sanctioned language of instruction in schools premised that it is the most familiar local language. Therefore, the million dollar question is: Are pupils and teachers familiar with SiLozi language as medium of instruction for initial literacy? If not,what implication does this have on epistemic access and initial literacy development? Subsequently, is SiLozi appropriate for literacy teaching and learning in the context of multilingualism in which the model prescribe a monolingual discourse in the Zambezi region of Namibia? Banda and Mwanza (2017) and Mwanza (2017) mentioned that in a multilingual classroom, there is need to bridge the home and school environment by drawing on the child's linguistic resources to help learners maximize their understanding and classroom performance. That is language should be viewed as a resource if effective teaching and learning is the goal of basic education. This entails that translanguaging may be the pedagogical language practice as it allows students to draw from their linguistic repertoires in the process of learning the target language and teachers accept it as legitimate pedagogical practice (Mwanza, 2017; Lasagabaster and Garcia (2014). Mwanza (2017) argued that learners should not be discriminated against from active participation in classroom interaction because they are not familiar with the target language of instruction for initial literacy. This means that language of instruction as key factor to effective teaching and learning should not be 
the creator of voiceless classrooms with shuttered independent thinking and decision-making which results in low literacy levels. However, it was not known the familiarity of teachers and learners with SiLozi language of instruction in pre-primary classrooms in an area where SiFwe was the predominant local familiar language.

\section{PuRPose OF THE STUdy}

The puporse of the study was to assess the familiarity of teachers and learners with SiLozi language of initial literacy teaching and learning in multilingual pre-primary classrooms and to determine whether SiLozi was appropriate as sole medium of instruction and the implication thereof on epistemic access and initial literacy development.

\section{CONCEPTUAL FrameWORK}

The three language orientation framework by Ruiz (1984) is used in this study. Ruiz (1984) looked at three orientation to language teaching and learning namely, language as a problem, language as a resource and language as a right. It is argued in this theory on the one hand that when multilingualism is regarded as a challenge, monolingual discourse premised on dominant/common language is deemed appropriate for instruction with the rationale of inclusiveness.On the other hand, diversity when viewed as resource, heterogrossic discourse becomes a resource for meaning making to acquire initial literacy and enable epistemic access. Thus, the way language is perceived, facilitates the manner in which it is applied.

A problem perspective on language: According to Ruiz (1984) advocates for educational program models that are monolingual in structure, with the rationale that linguistic minorities are best served by as much exposure to the dominant language as possible in the interest of "inclusiveness." This ideology emphasises the point that one language is powerful that the other and, hence, status is given to the (so called) powerful language. Thus, in most language classrooms to date one language dominates communication while devaluing other non-dominant languages which are more familiar to learners. This orientation brings to light the issue and stand point of the monolingual language policy programs in bi/multilingual settings that favours learning the dominant language at expense of losing their home language. Language as a problem orientation is thus exclusive as it sidelines other pedagogical discourses that are not official since linguistic diversity is perceived as a deficit and as a source of divisiveness. Therefore, this orientation with its notion of 'one jacket fits all' (Banda \& Mwanza, 2017) is not applicable for the development of initial literacy in a multilingual classroom.

Language as a right perspective essentially advocates for the entitlements of individuals and groups to actively use and maintain their languages in the social arena, and for access to interpreter services and tuition in the majority language (Harrison, 2007). Language as a right orientation is thus consistent with those societies whose philosophical drive is the principle of equality. This implies that all languages are equal, that there is no' strong and weak' language. This notion, extended to the classroom therefore, entails that all languages available should be valued as equal with the language of instruction and be equally used for meaningful learning.

Language as a resource orientation is the main drive and is the antithesis of language as a problem (Ruiz, 2010). Thus, under this orientation, the status of socially subordinated languages can be contested and enhanced, in the process of easing tension between dominant and minority language communities (Catalano \& Hamann, 2016). Through this orientation, language is viewed as a resource to be "managed, developed and conserved" and also "regard language minorities as important sources of expertise" (Ruiz, 1984:28). This orientation according to Martínez (2017) questions language hierarchies by valuing and encouraging bi/multilingualism. This orientation therefore suggests that language coexist interdependently and therefore, the values of each language and its community is acknowledged as part of the whole. When applied to the classroom, language as resource orientation allows for the use of multiple languages, has an additive perspective and therefore cognitive advantageous to the learners.

A resource perspective on language mirrors the pedagogical language practices such as translanguaging and code switching. However, in the later, languages are viewed as separate entities that can never be mixed. According to this study, language as a resource orientation is thus 
characterised by pedagogic language practices which ensure epistemic access and hence meaningful learning for initial literacy development.

The conceptualization of the three language orientations offers the positive and negative language ideologies. A problem perspective on language suggests the negative attitudes held towards either on own language or the languages of other people while language as a resource and as a right standpoints looks at the positive language ideologies towards both informal and formal languages. From a multilingual classroom perspective, negative views towards learners familiar but informal languages by teachers impedes the use of these languages, hence epistemic access is deprived off as well. On the other hand, positive perceptions towards both informal and formal languages by teachers promotes the use of multiple languages, hence enabling epistemic access.

Peirce (1989) cited in Martínez (2017) noted that teachers engage in a pedagogy of possibility, that is, a pedagogy that encourages teachers to reconsider which language discourse practices are possible. Also, citing Planas\& Civil, (2013), Martínez (ibid) stated that teachers' regulatory role may silence students' use of their preferred languages, potentially muting all contributions from particular students. Alternatively, teachers may enhance learning opportunities through the strategic and intentional use of students' languages. Thus, pre-primary teachers and pupils' familiarity with SiLozi also has pedagogical implications on the language practices of the teachers and pupils. In the context of the present study, if learners are not familiar with SiLozi language of instruction, it would require translanguaging in order to ensure epistemic access. If on the other hand, pupils are familiar, exclusivity of SiLozi as medium of instruction become useful as per policy provision.

Therefore, teachers being the implementers of government language policies they know best and understand their classroom contexts and situations. This implies that they are familiar with the suitable language practices that ensures epistemic access for their language classrooms. However, they are guided by power existing in these policies and thus would influence their practices. For the purpose of this study and in response to the major question of whether or not the pre-primary teachers and pupils were familiar with SiLozi the theory was used to understand the ideology in which SiLozi as language of instruction was framed in the pre-primary classrooms. Looking at the multilingual state of the Zambezi region and the language challenges in education, it is essential to understand the familiarity of the teachers and pupils with the sanctioned language of instruction. It is argued that using one language (monolingual classroom practice) to teach different learners of different familiar language backgrounds could result in symbolic violence leading to limited pupil participation and limited epistemic access and inadequate initial literacy development. Schroeder (2004) contends that where the languages are not native to pupils, many learners fail to speak or fully understand them. Consequently, these pupils do not understand the lessons taught using such mediums of instruction because they are not known to them. This confirms the short falls of using one language of instruction in a multilingual state. However, if language is viewed as resource, translanguaging will be used, implying that two or more languages will be employed to teach the pre-primary classrooms, it may limit symbolic violence and lead to democratization of the classroom, which in-turn would result to maximum pupil participation and full epistemic access for most learners and adequate initial literacy development.

\section{Methods of Data Collection And Analysis}

This is a mixed methods study using a convergent parallel design. The convergent parallel design entails that the researcher concurrently conducts the quantitative and qualitative elements in the same phase of the research process, weighs the methods equally, analyzes the two components independently, and interprets the results together (Creswell \& Pablo-Clark, 2011; Demir \& Pismek, 2018). Thus, both qualitative and quantitative methods were integrated concurrently in order to allow triangulation and cross-validation of the data in this study. Quantitave data collection involved the use of a familiar language test admistered to the pre-primary learners while the qualitative approach involved face to face interviews with 6 pre-primary teachers and 6 school principals drawn from six schools in Sibbinda Circuit of the Zambezi education region. The interviews were used to collect rich and detailed data pertaining teachers and learners' familiarity with SiLozi. Simple random sampling was used to select the six pre-primary classrooms which automatically involved 168 pupils who participated in the familiar language test while purposive sampling was employed to sample six 
The Language of Literacy Teaching and Learning in a Multilingual Classroom: Is Silozi Appropriate in the Zambezi Region of Namibia?

teachers and six school principals. The study area was Sibbinda Circuit in an area where SiFwe was the predominant familiar language. This was chosen based on the language policy relative to its socialinguistic context. The pre-primary classrooms were purposefully selected because this was the first class that experiences the switch of the home/familiar language ( $\mathrm{SiF} w e$ in this case) as they step into the use of SiLozi as medium of instruction. Quantitative data was analysed using the Statistical Package for Social Sciences (SPSS) while interview data was analysed thematically according to the research objective. Both quantitative and qualitative data were analysed and discussed in relation with the implication on initial literacy development and epistemic access in the pre-priamary.

\section{FINDINGS}

The following section presents the findings of the study.

\subsection{Familiarity of Teachers and Pupils with Silozi Language of Instruction}

The study was intended to assess the familiarity of both teachers and learners with SiLozi language of instruction. Data collected were both quantitative and qualitative. Quantitative data was collected from pupils using an oral familiar language test whereas qualitative data was collected from teachers and principals using semi-structured interviews.

\subsubsection{Pupils Familiarity with Silozi: Quantitative Data}

A familiar language test was administered to pupils to evaluate their familiarity with SiLozi language. It was administered by having twenty pictures with different objects and asked the pupils to name the object on the picture in SiLozi. Pupils' responses were recorded on the test paper and marked and scored. The assessment of object naming was out of 20 marks. The benchmark was set at an average score of $10 / 20$ on which pupils' performance was measured to determine familiarity. The score below 10/20 was considered to be below the set benchmark and thus translated as not familiar and the above 10/20 rated as good performance and familiar. The following were the data:

The results indicated that the learners' performance in the familiar language test was not good. Table 5.1 shows that only 45 learners representing $26.8 \%$ scored average and above, the rest who were 123 presenting $73.2 \%$ scored below average mark.

Table5.1. Pupils' Familiarity with Silozi

\begin{tabular}{|l|l|l|l|l|l|}
\hline \multicolumn{2}{|c|}{} & Frequency & Percent & V. Percent & C. Percent \\
\hline \multirow{2}{*}{ Valid } & below average & 123 & 73.2 & 73.2 & 73.2 \\
\cline { 2 - 6 } & average and above & 45 & 26.8 & 26.8 & 100.0 \\
\hline \multirow{2}{*}{} & Total & 168 & 100.0 & 100.0 & \\
\hline
\end{tabular}

The statistics shown in table 5.2 below illustrates that majority of the learners (73.2\%) scored below average mark and only a few $(26.8 \%)$ scored average and above. This indicates that many pupils (123) were not familiar with SiLozi medium of instruction and only a few (45) were.

Table5.2. Pupils Familiar Language Test Scores

\begin{tabular}{|c|c|c|c|c|c|}
\hline & Marks & Frequency & Percent & V. Percent & C. Percent \\
\hline & 0 & 2 & 1.2 & 1.2 & 1.2 \\
\hline & 1 & 2 & 1.2 & 1.2 & 2.4 \\
\hline & 2 & 15 & 8.9 & 8.9 & 11.3 \\
\hline & 3 & 35 & 20.8 & 20.8 & 32.1 \\
\hline & 4 & 18 & 10.7 & 10.7 & 42.9 \\
\hline & 5 & 14 & 8.3 & 8.3 & 51.2 \\
\hline & 6 & 9 & 5.4 & 5.4 & 56.5 \\
\hline & 7 & 8 & 4.8 & 4.8 & 61.3 \\
\hline & 8 & 12 & 7.1 & 7.1 & 68.5 \\
\hline Valid & 9 & 8 & 4.8 & 4.8 & 73.2 \\
\hline & 10 & 8 & 4.8 & 4.8 & 78.0 \\
\hline & 11 & 12 & 7.1 & 7.1 & 85.1 \\
\hline & 12 & 5 & 3.0 & 3.0 & 88.1 \\
\hline & 13 & 3 & 1.8 & 1.8 & 89.9 \\
\hline
\end{tabular}


The Language of Literacy Teaching and Learning in a Multilingual Classroom: Is Silozi Appropriate in the Zambezi Region of Namibia?

\begin{tabular}{|l|l|l|l|l|l|}
\hline \multirow{2}{*}{14} & 2 & 1.2 & 1.2 & 91.1 \\
\cline { 2 - 7 } & 15 & 9 & 5.4 & 5.4 & 96.4 \\
\cline { 2 - 6 } & 16 & 5 & 3.0 & 3.0 & 99.4 \\
\cline { 2 - 6 } & 18 & 1 & .6 & .6 & 100.0 \\
\hline
\end{tabular}

Table 5.3 below also confirms that pupils were more familiar with the vocabulary of other languages than with the vocabulary of SiLozi medium as shown by pupils' responses.

Table5.3. Pupils' Familiarity with SiLozi

\begin{tabular}{|l|l|l|l|}
\hline$\#$ & $\begin{array}{l}\text { Name of Object } \\
\text { in English }\end{array}$ & $\begin{array}{l}\text { Name of Object in } \\
\text { standard SiLozi }\end{array}$ & Names of Object according to Pupils Responses \\
\hline 1 & Baby & Mbututu/Lukeke & Mbumbu, baby, mwanche, mwanuke, \\
\hline 2 & Door & Sikwalo & Sikwalo, siyazo, ciyazo, cigwaro, door \\
\hline 3 & Chair & Sipula & Sipula, chipura, chair, makaro \\
\hline 4 & Hands & Mazoho & Mazoho, mayanja, mayanza, hands \\
\hline 5 & Tree & Kota & Sikota, kota, cikuni, sikunicisamu, thitondo, tree \\
\hline 6 & Dog & nja & Ebwa, ombwa, umbwa, njanana, dog, libwa, nja \\
\hline 7 & Table & Tafule & Ntafule, tafule, table \\
\hline 8 & Window & Lihaulo & Nji window, windo, nji glass, \\
\hline 9 & Snake & Noha & Kungwe, njoka, ezyoka, snake, noha \\
\hline 10 & Cow & Komu & Ñombe, citore, mpene, komu, cow \\
\hline 11 & Keys & Linotolo/likii & Keys, likii, makii, nzinkii \\
\hline 12 & Eyes & Meeto & Menso, mensho, eyes, meeto \\
\hline 13 & Teeth & Meeno & Meeno, meno, teeth \\
\hline 14 & Bicycle & Kanamutendele/njinga & Njinga, injinga, njinjinga, bicycle \\
\hline 15 & Vehicle/ Car & Mota/Motikala & Mota, imota, njimota, simbayambaya, car \\
\hline 16 & Sun & Lizazi & Kamwi, zyuba, izuba, lizazi, sun, diyuwa \\
\hline 17 & Elephant & Tou & Unzovu, ndunjovu, tau, tou, elephant \\
\hline 18 & House & Ndu & Situngu, citungu, njuo, inzuvo, ndu, house \\
\hline 19 & Book & Buka & Imbuka, njimbuka, njibuka, buka, book \\
\hline 20 & Bag & Mukotana & Bag, mukotana, kabegi \\
\hline
\end{tabular}

\subsubsection{Pupils Familiarity with Silozi: Qualitative Data}

The qualitative data from interviews revealed that pupils were not familiar with SiLozi language. Teachers and principals mentioned that pupils did not have SiLozi background since they spoke and came from homes with different languages and SiLozi was solely met as a new language in class during lessons. Below are some of their responses:

TB: It is difficult for these children to understand SiLozi because when they are at home they are using SiFwe as their mother tongue...they are not familiar with SiLozi.

TC: The learners also are not proficient, it is even worse for them because they are meeting this language only in class during lessons.

TD: They are not proficient. In fact, they don't understand SiLozi unless you translate in their mother tongue is when they can understand.

TE: These learners are not fluent in SiLozi since they don't use it at home... SiLozi is a new language to them... they speak different languages like SiFwe, Mbukushu and others here so I have to translate in their mother tongue.

TF: Most of these learners are not speaker of SiLozi and so it is difficult for them, only some are proficient in SiLozi because it's their mother tongue and they come from kindergarten in town where they use English and SiLozi sometimes.

PA: ... for the pre-primary learners, SiLozi is difficult to catch up because it's a new language to them. They come from homes with different languages and SiFwe is the most spoken language here. Children are not familiar with the SiLozi as medium of instruction.

PC: Leaners are not proficient in SiLozi since it not their first language, they are more proficient in SiFwe because it is their mother tongue 
The Language of Literacy Teaching and Learning in a Multilingual Classroom: Is Silozi Appropriate in the Zambezi Region of Namibia?

PD: SiLozi is difficult for these learners to understand, they are coming from homes with their own languages. In short they are not proficient, so they will continue struggling, so it is better to interpret in SiFwe when teaching.

Both familiar language test and interviews confirmed that many pupils were not familiar with SiLozi language being used for literacy teaching and learning.

\subsubsection{Teachers' Familiarity with Silozi}

Commenting on the teachers' familiarity with SiLozi language, majority (4) of the school principals stated that teachers were familiar with SiLozi, based on the fact that SiLozi was a national language and mother tongue within the region. They also mentioned that teachers had learnt SiLozi in school and were pursuing further studies in the same language (SiLozi). However, it was noted that SiLozi was not a familiar language for most teachers. A few (2) were of the view that teachers were not familiar since they did not have necessary academic professional qualifications, thus were not fully qualified. They said the following:

PA: I think the teacher is not really proficient because she is getting difficulties since learners don't understand the language.

PB: Silozi is a mother tongue and national language within the Zambezi region. So the teacher is proficient in SiLozi that is why she is qualified to teach these learners.

PC: ....Some of them are in training, so they are not 100\% proficient because they are underqualified ...

PD: The pre-primary teacher is not really qualified, she is busy studying but as far as SiLozi is concerned she has it on the grade 12 certificate.

PE: The teacher is taking SiLozi as a second language not necessarily first language, she is SiFwe-speaking by tribe, so she learnt SiLozi at school, and it is an acquired language but competency wise I think she is well.

$P F:$ I think the teacher is trying since she is furthering her studies.

Teachers were asked to give their opinion on their familiarity with Silozi, most (4) said that they were familiar with SiLozi and one of the teachers even said that she studied the language (SiLozi) at higher institutions of learning. Two of the six teachers stated that they were not so familiar with SiLozi and the reason mentioned was that it was not their mother tongue. Therefore, it was challenging to find new words and meanings of some words as they were required to translate those words into the learners' familiar languages. They said the following:

TC: I cannot say I am fluent because I have problems here and there with some of the words because we have to translate from English to SiLozi, like our syllabuses are in English so we have to translate the lessons from English to SiLozi.

TE: It is difficult to use SiLozi proficiently because it not my mother tongue... I am also learning the language, so finding new words and translating those into the mother tongue of my children is not ease.

Finding from both quantitative and qualitative data showed that many pupils were not familiar with SiLozi medium of instruction. Findings also revealed that majority teachers were familiar with SiLozi.

\section{DISCUSSION}

This study sought to address the question of whether the language of literacy teaching and learning was appropriate in the context of multilingualism in which the model prescribe a monolingual discourse and the implication thereof on epistemic access and initial literacy development. To do that, the study focused and assessed the familiarity of both pupils and teachers with SiLozi as the sanctioned language of instruction in the Zambezi region of Namibia. Discussed below are the study findings. 
The Language of Literacy Teaching and Learning in a Multilingual Classroom: Is Silozi Appropriate in the Zambezi Region of Namibia?

\subsection{Teachers and Pupils' Familiarity with Silozi}

The findings revealed that most of the pupils were not familiar with SiLozi language of instruction. The oral familiar language test has shown that $73.2 \%$ presenting 123 pre-primary scholars scored below average mark and only $26.8 \%$ representing 45 learners scored average and above. These statistics shows that majority pupils' performance in SiLozi language of instruction was poor, which meant that many pupils were not familiar with SiLozi medium of instruction. NIED (2011) established that the general performance of Grade one pupils in the literacy test was way below the benchmark. Similarly, the 2011 results of the national standardized tests carried out in grades 5-7 in English, Mathematics and Science, revealed that the Namibian learners were underachieving, particularly in English and Mathematics (Sasman, 2011). Low achievements of the pre-primary scholars in the familiar language test are consistent with these findings and the attribution of poor performance to lack of familiarity with the language of instruction. Thus, pupils were not familiar with Silozi, hence poor results in the familiar language test. Therefore, it is asserted here that an inadequate knowledge of SiLozi is one of the major factors contributing to low literacy levels in the junior primary which also overlaps to the senior primary and other grade levels. Thus, the use of SiLozi as exclusive language of instruction in the pre-primary leaves pupils not adequately equipped to handle complex basic literacies in further grades in SiLozi and English.

Zulu (2019) and Mwanza (2012) noted that lack of familiarity with the language of instruction results into poor achievements by pupils. Tambulukani and Bus's (2009) cited by Zulu (2019) argued that when learners lack familiarity in the language of initial literacy instruction, they might experience significant difficulties in developing literacy skills in the target language of instruction. Subsequently, pre-primary scholars' poor performance in the familiar language test were due to lack of familiarity with SiLozi as language of instruction for initial literacy. Thus, a lack of familiarity with the language of literacy teaching and learning is partially the root cause for low literacy rates among pre-primary learners who are found in Namibian schools in which diverse languages are spoken. Familiarity with the language of instruction instils confidence and knowledge of many things if not everything because pupils learn from known to unknown. However, lack of it impedes cognitive perception, if pupils struggle to master an unfamiliar language and find difficulties to express themselves in it, they instead of enthusiasm, develop anxiety and lose confidence and interest to enquire for more (Totemeyer, 2010). In a classroom context, pupils cannot participate in an interaction which promotes learning. They become voiceless and development of independent thinking and decision-making is shuttered. As a result many children lose zeal to learn when taught in a language they struggle to understand and literacy achievement dwindles and episteme access is disabled.

Therefore, pupils should not be discriminated against from participating in classroom interaction simply because they are not familiar with the target language for initial literacy (Mwanza, 2017). Language is a resource for meaning making, therefore, familiar language of instruction enables learners the necessary tools for understanding, for formulating questions and points for discussion or to think critically while learnining initial literacy in SiLozi. When pupils are confident and well equipped in their familiar language, it faciltates mastering the target and other language (s) (SiLozi and English). Therefore, familiarity with the language of instruction means that children will make meaning out of any task across the curriculum and complete it successfully (Ministry of Eduction, 2014).Literacy is the most important skill for learning in school and familiar language is the main means of developing understanding of the contents of the syllabus. Literature advocate the idea of laying a foundation in multiple languages in heterogeneous classrooms as this helps learners to understand things concretely and with ease. This means that children will just be more fluent and confident when they learn through their familiar languages when starting the Pre-Primary school.

Findings from the interviews also showed that pupils were not familiar with SiLozi. Teachers and principals stated that pupils were not familiar with SiLozi language. They mentioned that most pupils did not have SiLozi background since they spoke different local languages in their homes which they also went with to school while SiLozi was solely met as a new language in class during lessons. It is argued that lack of familiarity in the instructional language hinders epistemic access and disadvantages the previous academically disadvantaged groups even more (Mwinda\& van der Walt, 2015). In that regard, Lewis, Jones and Baker (2012) argue that in a multilingual classroom, there is need therefore to bridge the home and school environment by drawing on the child's linguistic 
resources to help learners maximize their understanding and classroom performance. This means that language should be viewed as a tool for ensuring epistemic access and initial literacy development. Thus, translanguaging should be regarded as the most suitable approach to achieve effective teaching and learning of initial literacy in SiLozi medium where majority of the pupils are not familiar with the language of literacy teaching and learning. As a pedagogical practice, translanguaging entails allowing students to draw from their home languages in the process of learning the target language and teachers accept it as legitimate pedagogical practice (Lasagabaster and Garcia, 2014). That is, initial literacy instruction when given in a familiar language is more effective and meaningful, because it enables pupils to learn from unknown to known. At the same time, when the language of instruction is familiar to both the teacher and learners, the teacher can establish if learning has taken place or not and be able to identify the learning challenges experienced by learners and which learners requires further assistance. In other words, it becomes ease for teachers to determine whether pupils have difficulty in understanding the concept itself or the language of instruction (Magulu, 2016). This implies that instruction in a familiar language is relevant for meaningful learning to the child, since it facilitates the transfer of linguistic skills to acquire the language of instruction in a multingual environment.

Therefore, considering the fact that most pupils were not familiar with SiLozi medium, one teacher (TD) mentioned that unless she interpreted the lesson in the local familiar language that is when pupils understood. In fact, one principal (PD) mentioning SiFwe suggested that it was better to interpret in the familiar language when teaching pre-primary children in SiLozi medium. The implication of this is that the exclusive use of SiLozi disabled epistemic access and initial literacy development. The teacher' and principal's views suggest that language is resource to ensure meaningful learning to the pre-primary children and attain vocabulary of the target language instruction. Thus, the two participants were confirming and suggesting that translanguaging, where the local familiar language was used in support of SiLozi (multiple languages) was the most suitable pedagogical practice to ensure epistemic access and initial literacy development in SiLozi medium classrooms. Garcia and Li-Wei (2014) observes that translanguaging involves issues of language production, the function of language and thought process behind language use. Moreover, Riegelhaupt (2000) states that the teacher creates a scaffold by using both languages alternately to convey increasingly specific and complex information, while connecting the new information to the information already presented. Thus, instruction in multilingual junior primary classrooms was effective with the use of multiple languages (Koker, 2019; Mkandawire, 2017). It is noted from the findings that lack of familiarity in the language of instruction disables epistemic access and makes learning very challenging and retrogressive. As can be noted from the performance of learners in the familiar language test results that their achievements were very low.

With regard to teachers' familiarity with SiLozi, the findings revealed that most teachers were familiar with SiLozi language of instruction. The teachers and school principals mentioned that teachers were familiar with SiLozi since it was a national and predominant spoken local language in the Zambezi region. They also mentioned that teachers studied SiLozi during their school careers and were pursuing further studies in the same language (SiLozi). However, it was noted that SiLozi was not a familiar language for all the teachers. As such, the findings also revealed that some teachers (two) were not familiar with SiLozi. They mentioned that sometimes they lacked vocabulary to interpret some concepts to aid pupils understanding. This could also be associated to their lack of academic professional qualifications. However, the point to note is that teacher's lack of familiarity with the medium of instruction worsens the situation of those pre-primary children who were also learning initial literacy not in their familiar language. This means that when teachers and learners becomes strangers to the language used for instruction, literacy achievements among pupils who were learning the language for the first time will be poor. Therefore, learners' failure to breakthrough to initial literacy in SiLozi may be related to pupils and teachers lack of familiarity with the target language of instruction.

In brief, the results on teachers and learner familiarity with SiLozi revealed that most learners and some teachers were not familiar. It can be concluded that familiarity in the language of instruction is a pre requisite, and significant in the classroom, since language plays a central role in the teaching and 
learning process. Learning in an unfamiliar language creates challenges to learners and their teachers, and it is acknowledged that it is this language that acts as a barrier to learning and affects the pupils' performance. Hence, it is very important that teachers who find themselves in bilingual or multilingual classroom where the language not familiar to pupils is utilized find strategies that enable them to handle their learners' linguistic challenges (Shilamba, 2012).

\subsection{Conclusions and Pedagogical Implications}

The three language orientation framework makes reference to language planning in an academic context. The study concludes that the exclusive use of SiLozi as medium of instruction for initial literacy in the pre-primary is as result of the view that language is a problem. Therefore, it seeks to remedy this deficit with subtractive language teaching (Hult, 2014), with the rationale that linguistic minorities are best served by as much exposure to dominant language as possible in the interest of inclusiveness.

The present study confirms that the pre-primary classrooms in multilingual contexts is not and should not be perceived to be monoglossic, as educational programs that follow from the language as a problem orientation tend to be exclusive in nature. It promotes limited learner participation and limited pupil epistemic access. It sidelines the pupils' most familiar language (s) that inevitably and fortunately serves as tools for pupils' interaction. Schroeder (2004) contends that where the languages are not native to pupils, many learners fail to speak or fully understand them. Consequently, these pupils do not understand the lessons taught using such mediums of instruction because they are not known to them and fail in their linguistic and literacy acihevements.

Pupils use their linguistic resources to interconnect effectively and understand their enviroments. Therefore, the linguistic tools learners come with to the clasrroom can serve diverse purposes as discovered in this study. In particulaar, language as resource helps (i) to mediate understanding, (ii) to learn the target language and (iii) to co-construct meaning. Thus, rather than a deficit or failure, the deployment of all linguistic resources is an opportunity to learn the target language and develop requisite vocabulary and literacies for academic purpose and progression. It is concluded in this study that language as resource gives a vivid and more realistic view of the linguistic realities on the ground both inside and outside the school. Therefore, the flexible use of the entire pupils' linguistic resources may be beneficial to support the language learning goal. However, this does not mean other languages should be overused as a way to teach initial literacy, but the argument is that they should not be forbidden as they help students make links between languages and ensures multiteracy development.

Language as resource is considered inclusive in nature and integrational as it accommodates and educates all children in the classroom, regardless of their linguistic and cultural background. This framework support their language learning goal and fosters democratization in the classroom as it promotes maximum learner participation and maximum epistemic access. Thus, it may help increase interaction between teachers and pupils and among pupils themselves by accepting other languages into the SiLozi meduim pre-primary classroom. Therefore, language as a resource through the employment of translanguaging as a pedagogical approach may help engender multilingualism, counteract symbolic violence and ensure epistemic access and facilitate initial literacy development.

It is concluded in this study, therefore, that the exclusive use of SiLozi is not appropriate as language of literacy teaching and learning in a multingual context since it was established that many pupils as core beneficiaries of the language of instruction were not familiar. The study established that translanguaging aided pupils to attach meaning and acquired the SiLozi target language vocabulary. When translanguaging is the medium of isntruction, both teachers and pupils in particular will be able to compare the lexis in their indigenous familiar language to that of the SiLozi target language, hence develop multiliteracies. Teachers should be allowed to use multiple languages in the junior primary (pre-primary) as it improves pupils'target language literacy development and facilitates epistemic access. Translanguaging should be viewed by teachers, school managers and curriculum developers as an alternative pedagogical resource strategy that may enable epistemic access and ensure initial literacy development. 
The Language of Literacy Teaching and Learning in a Multilingual Classroom: Is Silozi Appropriate in the Zambezi Region of Namibia?

\section{REFERENCES}

[1] Banda, F., \& Mwanza, D.S. (2017). Language-In-Education Policy and Linguistic Diversity in Zambia: An Alternative Explanation to Low Reading Levels among Primary School Pupils. In B. (. Khulupirika, Selected readings in education (pp. 109-132). Lusaka: University of Zambia Press.

[2] Benjamin, E. (2004). A Case Study on the influence of English as a Medium of Instruction on Learners Academic Performance at Du Plessis Secondary School and Shikongo Iipinge Senior Secondary School. MEd Thesis. Unpublished: University of Namibia.

[3] Catalano, T., \& Hamann, E. (2016). Multilingual pedagogies and pre-service teachers: Implementing "language as a resource" orientations in teacher education programs. Bilingual Research Journal 39, 263-278.

[4] Creswell, J. W., \& Plano Clark, V. L. (2011). Designing and conducting mixed methods research. Thousand Oaks, CA:: Sage.

[5] Demir, S., \& Pismek, N. (2018). A Convergent Parallel Mixed-Methods Study of Controversial Issues in Social Studies Classes: A Clash of Ideologies. Educational Sciences: Theory \& Practice, DOI 10.12738/estp.2018.1.0298 $\square$ February $2018 \square 18(1) \square 119-149$.

[6] Garcia, \& Li-Wei. (2014). Translanguaging: Language, Bilingualism and education. Palgrave Mac-millan.

[7] Harris, P. (2011). Language in Schools in Namibia: The Missing Link in Educational Achievement? Windhoek: The Urban Trust of Namibia Monograph No 1.

[8] Harrison, G. (2007). Language as a Problem, a Right or a Resource? A Study of How Bilingual Practitioners See Language Policy Being Enacted in Social Work. Journal of Social Work, 7(1): 71-92.

[9] Iipinge, K. (2013). English lingua franca as language of learning and teaching in Northern Namibia: A report on Oshiwambo teachers' experiences. Unpublished master's thesis. Cape Town: University of Stellenbosch.

[10] Iitula, L. (2016). Linguistic identity in the Namibian context, New Era Newspaper Namibia. 23 November 2016. retrieved on www.newera.com.na date 12.03.2018.

[11] Kangumu, B. K. (2008). Contestations over Caprivi Identities: From Pre-Colonial Times to the Present. University of Cape Town.

[12] Kavhura, J. (2018). Indigenous Languages in Regional Education: A Case of Namibia. MA Thesis. Unpblished: University of Eastern Finland.

[13] Koker, J. (2019). An Investigation of Challenges Experienced by Teachers Who are Teaching through Africaans Medium Of instrcution: A Case of Four Selected Primary Schools in Windhoek. MEd Thesisi, Unpblished: University of Namibia.

[14] Kombe, C., \& Mwanza, D. S. (2019). The 2014 Zambian Revised Literacy Policy in Primary Schools: Were Teachers Prepared to Implement It? International Journal of Humanities Social Sciences and Education (IJHSSE), 6(8), 115-131.

[15] Lasagbaster, D., \& Ofelia, G. (2014). Translanguaging: Towards a Dynamic Model of Bilingualism at School / Translanguaging: hacia un modelo dinámico de bilingüismo en la escuela. Culture and Education, 26(3), 557-572.

[16] Lewis, G., Jones, B., \& Baker, C. (2012). Translanguaging: Developing its Conceptualisation and Contextualisation. Educational Research and Evaluation, 18(7) , 655-670.

[17] Maclaren, P. (1958). The fishing devices of central Africa and southern Africa, Occasional papers of Rhodes 12. Livingstone: Livingstone Institute.

[18] Magulu, H. (2016). The Impact of the Language of Instruction on Teacher-Pupils Classroom Interaction in History Subject in Primary Schools in Tanzania. Master Thesis. Unpublished: University of Oslo.

[19] Martínez, J. (2017). Realization of a Language-as-Resource Orientation in Language Immersion Mathematics Classrooms. In E. Galindo, \& J. Newton (Ed.), Proceedings of the 39th annual meeting of the North American Chapter of the International Group for the Psychology of Mathematics Education (pp. 1163-1169). Indianapolis, IN: Hoosier Association of Mathematics Teacher Educators.

[20] Mbala, R. (1996). African Languages in Basic Education. Silozi in Basic Education. . Proceedings of the first Workshop on African Languages in Basic Education (pp. 264-271). Okahandja: NIED.

[21] Ministry of Education. (2014). Junior Primary Phaes: Pre-Primary Teachers' Manual. Okahandja: National Institute for Educational Development (NIED).

[22] Mkandawire, S. B. (2017). Familiar Language Based Instruction Versus Unfamiliar Language for the Teaching of Reading and Writing Literacy Skills: A Focus on Zambian Languages and English at Two Primary School in Lusaka. Zambia Journal of Language Studies, 53-81. 
The Language of Literacy Teaching and Learning in a Multilingual Classroom: Is Silozi Appropriate in the Zambezi Region of Namibia?

[23] Mwanza, D. S. (2012). The Language of Initial Literacy in a Cosmopolitan Environment: A Case of Cinyanja in Lusaka District. Unpblished MED Dissertation. Lusaka: The University of Zambia.

[24] Mwanza, D. S. (2017). Implications of Teachers' Attitudes towards Unofficial languages on English Language Teaching in Multilingual Zambia. Zambian Journal of Language Studies, 1(1), 101 - 124.

[25] Mwanza, D.S. (2017). Teachers' Understanding and Attitudes towards the Eclectic Method to $01-16$ Language Teaching in Zambia. Journal of Educational and Management Studies. 7

[26] Mwanza, D.S (2017). The Eclectic Method to language Teaching: Clarifications and Conceptual Extensions. Journal of Lexicography and Terminology. 1 (2), 1-24.

[27] Mwinda, N., \& van der Walt, C. (2015). From 'English-only' to translanguaging strategies: Eploring possibilities. Per Linguam, 100-118.

[28] NIED. (2011). An Investigation of Literacy and Numeracy Skills at lower Primary Phase in Namibian Schools. NIED Okahandja: Research Unit, Division Professional, Resource Development and Research,.

[29] Nzwala, K. (2015). Challenges Faced by Student Teachers when Teaching Through the Medium of Mother Tongue during School Based Studies: A Case for Katima Mulilo Campus Bachelor of Education 4 (Pre \& Lower Primary) Students.

[30] Riegelhaupt, F. (2000). Code switching and language use in the classroom. Northern Arizona University. Somerville, MA: Cascadilla Press.

[31] Ruiz, R. (1984). Orientations in language planning. . NABE Journal, 8, , 15-34.

[32] Ruiz, R. (2010). Reorienting language-as-resource. In J. P. (Ed.), International perspectives on bilingual education: Policy, practice, and controversy (pp. 155-172). Charlotte, NC: Information Age.

[33] Sasman, C. (2011). Grade 7 tests show disappointing results. The Namibian. Retrieved from http://www.namibian.com.na/index.php?id=28\&tx_ttnews\%5Btt_news\%5D=84622\&no_cache=1

[34] Schroeder, L. (2004). Mother tongue Education in Kenya: Some hidden beneficiaries. Language Matters, 35 (2).

[35] Shilamba, J. (2012). An Invesitigation into the Prevalence and use of Code Switching Practices in Grade 8 Mathematics Classrooms in the Ohangwena Region of Namibia: A Case Study. MEd Thesis: Rhodes University.

[36] Sitwala. (2010). Language Maintanance in the Malozi Community of Caprivi. MA Thesis: University.

[37] Steigertahl, H. (2018). Similarities and differences between varieties of speech: Expressions of language ideologies and attitudes in four Namibian communities. SOAS Working Papers in Linguistics, 133-153.

[38] Tötemeyer, A. (2010). Multilingualism and the language policy for Namibian schools. PRAESA Occasional Papers No. 37. Cape Town: PRAESA.

[39] ZuLu, A. J. (2019). An Analysis of Transitional Language Practices Among Garde Five Teachers and Learners in Selected Primary Schools of Chongwe District, Lusaka. MEd Thesis, Lusaka: University of Zambia.

Citation: Begani Ziambo Mashinja, David Sani Mwanza. "The Language of Literacy Teaching and Learning in a Multilingual Classroom: Is Silozi Appropriate in the Zambezi Region of Namibia?" International Journal of Humanities Social Sciences and Education (IJHSSE), vol 7, no. 3, 2020, pp. 31-42. doi: http://dx.doi.org/10.20431/2349-0381.0703005.

Copyright: (C) 2020 Authors. This is an open-access article distributed under the terms of the Creative Commons Attribution License, which permits unrestricted use, distribution, and reproduction in any medium, provided the original author and source are credited. 